\title{
Repeat hepatectomy for recurrent hepatocellular carcinoma: a local experience and a systematic review
}

Yanming Zhoư1,2, Chengjun Suit2, Bin Li1 , Zhengfeng Yin*3, Yunchang Tan², Jiamei Yang*2 and Zhenyu Liu³

\begin{abstract}
Background: This study aimed to assess the efficacy and safety of repeat hepatectomy for recurrent hepatocellular carcinoma (HCC).

Methods: Thirty-seven patients who underwent a curative repeat hepatectomy in our hospital were retrospectively studied. An extensive database literature search was performed to obtain for all relevant studies.

Results: In our series, there were no perioperative deaths during repeat hepatectomy for recurrent HCC. Patients survival after repeat hepatectomy were similar to 429 patients undergoing initial hepatectomy. A computerized search of the Medline and PubMed databases found 29 retrospective studies providing relevant data in 1149 patients were included for appraisal and data extraction. After the repeat hepatectomy, postoperative morbidity ranged from $6.2 \%$ to $68.2 \%$ with a median per cohort of 23.5 per cent. There were 7 perioperative deaths $(0.7$ per cent of 993 for whom mortality data were provided). The overall median survival ranged from 21 to 61.5 months, with 1 -, 3 -, and 5-year survival of $69.0 \%$ to $100 \%, 21.0 \%$ to $87.0 \%$, and $25.0 \%$ to $87.0 \%$, respectively.

Conclusions: Repeat hepatectomy can be performed safely and is associated with long-term survival in a subset of patients with recurrent HCC. However, the findings have to be carefully interpreted due to the lower level of evidence. A randomized controlled study is needed to compare repeat hepatectomy and other modalities for recurrent HCC.
\end{abstract}

\section{Background}

Hepatocellular carcinoma (HCC) is the fifth most common cancer in the world, responsible for 500,000 deaths globally every year, and its incidence is increasing worldwide because of the dissemination of hepatitis $B$ and $C$ virus infection [1]. With advances in surgical techniques and perioperative care, results of hepatic resection for HCC have greatly improved. Nonetheless, the long-term survival after hepatectomy remains unsatisfactory because of the high incidence of recurrence. Intrahepatic recurrence are the most common and are seen in up to $68-96 \%$ of patients [2]. Thus, effective therapeutic strate-

\footnotetext{
*Correspondence: yinzfk@yahoo.com.cn, yjm.1952@yahoo.com.cn

3 Department of Molecular Oncology, Eastern Hepatobiliary Surgery Hospital, Second Military Medical University, Shanghai, China

2 Department of Special Treatment and Liver transplantation, Eastern Hepatobiliary Surgery Hospital, Second Military Medical University, Shanghai, China

+ Contributed equally

Full list of author information is available at the end of the article
}

gies of intrahepatic recurrence is critical in prolonging survival after resection of HCC.

Transcatheter arterial chemoembolization (TACE) is most commonly used as a treatment modality for intrahepatic recurrence. However, the role of TACE therapy in the treatment of postoperative recurrence is pessimistic, with 5 -year survival rates only range from $0 \%$ to $27 \%$, even with repeated TACE treatment [3-5]. Hepatic resection is the only therapy that is potentially curative for liver tumors, and offers patients a chance of long-term survival. Currently, many treatment centers advocate the repeat hepatectomy is the first choice of treatment for recurrent $\mathrm{HCC}$ and have claimed that it is safe and that it has similar survival results to initial hepatectomy [6]. However, due to the limited numbers of patients who undergo resection at a single institute, a thorough assessment of the outcome of repeat hepatectomy for recurrent $\mathrm{HCC}$ has not been reported. 
In this study, based on literature review and retrospective results from our institution, we assessed the efficacy and safety of repeat hepatectomy for recurrent HCC.

\section{Methods \\ The author's experience \\ A) Patients}

From December 1999 and June 2005, 462 patients with HCC underwent initial hepatic resection with curative intent at the Department of Special Treatment and Liver transplantation in Eastern Hepatobiliary Surgery Hospital, Second Military Medical University, Shanghai, China. Curative resection was defined as grossly complete removal of the tumor with a clear microscopic margin. Four patients died within 1 month after operation and 29 patients lost follow-up were excluded from the present study. The remaining 429 patients were followed-up every 1 month by tumor marker (alpha-fetoprotein, AFP) analysis and ultrasound or computed tomography at least every 3 months in the first year after hepatectomy, and then at gradually increasing intervals. Recurrence was identified by new lesions on imaging with appearances typical of $\mathrm{HCC}$ or a rising AFP level. When findings on ultrasound or computed tomography were inconclusive, hepatic angiography with infusion of iodized oil was performed.

During a median follow-up period of 25 months, 276 (64.3\%) patients developed intrahepatic recurrence, and 37 patients underwent a second hepatectomy (rate of repeat hepatectomy, 13.4\%). There were 32 men and 5 women with a median age of 52 years (range, 16 to 81 years) at the time of the second operation. Our selection criteria for repeat resection were the same as those for initial resection: good general condition, favorable ChildPugh Class (A plus selected Grade B), adequate liver remnant, and the ability to technically resect all tumor with curative intent. Treatments for unresectable intrahepatic recurrence were TACE $(n=126)$, local thermal and chemical ablation $(n=45)$, and only conservative management $(\mathrm{n}=68)$.

\section{B) Operative procedures}

Surgery was performed through a right or left subcostal incision or bilateral subcostal incision. After an exploratory laparotomy, the liver was fully mobilized from all its peritoneal attachments. The liver was then assessed with intraoperative ultrasound to assess the extent of local disease, and to detect any extrahepatic metastases or peritoneal seedings. A Pringle maneuver was carried out for controlling the portal triad, with a clamp/unclamp time of $15 \mathrm{~min} / 5 \mathrm{~min}$, during hepatic parenchymal transection if necessary. Transection of the liver was achieved using the Kelly clamp crushing technique. The vascular and biliary radicals were ligated and divided intrahepatically. Fibrin glue was applied to the raw surface of the liver.
Nomenclature for the extent of hepatic resection follows the Brisbane 2000 Guidelines for Liver Anatomy and Resection [7]. Major resection were defined as a resection of 3 or more segments, whereas minor resection were defined as a resection of 2 or fewer segments according to the Couinaud classification. Perioperative mortality was defined as any death either within 30 days of surgery or occurring in the hospital.

\section{C) Statistical analysis}

Categorical variables were compared by using the Chisquare test or the Fisher exact test as appropriate. Continuous data were expressed as the mean \pm standard deviation and compared by one-way ANOVA. Mann-Whitney $\mathrm{U}$ test was used to evaluate differences between groups. Overall survival rates were estimated with the KaplanMeier method and compared by log-rank test. The Cox proportional hazards model was used for multivariate analysis of prognostic factors. All statistical analyses were performed using SPSS for Windows (version 11.0; SPSS Institute, Chicago, IL, USA). $P<0.05$ was considered statistically significant.

\section{Systematic review}

\section{A) Literature search}

Electronic literature searches were performed to identify all published peer-review medical articles on repeat hepatectomy for recurrent HCC. Medline and PubMed databases were searched from the time of inception to November 2009. The following Mesh search headings were used: "recurrent hepatocellular carcinoma," "repeat hepatectomy," "repeat hepatic resection," and "second hepatectomy." Reference lists of all retrieved articles were manual searched for additional studies.

\section{B) Selection criteria}

For inclusion in review, studies that reported at least 10 patients and that used repeat hepatectomy for recurrent HCC with a curative intent were retrieved. Studies were classified into 4 levels of evidence as follows: level 1, randomized controlled trials; level 2, controlled clinical trials; level 3, observational studies with matched control groups; and level 4, observational observational case series. Letters, reviews, abstracts, editorials, expert opinions, non-English language papers and animal studies were excluded. Studies that included other liver cancer diagnoses were excluded. In the case of multiple publication of a given cohort of patients, the first published article was included in our analysis. However, if a more recent publication corroborated the results of a larger cohort, longer follow-up, or both, we included this more recent publication.

\section{C) Data extraction and critical appraisal}

Data extraction was performed independently by two authors (Y.M.Z. and B.L., respectively) using predefined criteria. The two investigators independently reviewed all 
the retrieved studies that met the inclusion and exclusion criteria. Discrepancies between the two reviewers were resolved by discussion and consensus. Each included study was appraised for its level of evidence. The two reviewers extracted data on the following categories: (1) number of patients undergoing surgery for recurrent HCC; (2) resectability rate; (3) postoperative morbidity and mortality; (4) overall survival; (5) prognostic factors. A meta-analysis was not possible because none of the studies were randomized trials. All relevant text, tables and figures were reviewed for data extraction. Data are presented as median (range) unless otherwise stated.

\section{Results}

\section{The author's experience}

Table 1 shows a comparison of the clinicopathological features, operative procedures and perioperative outcomes among the 462 patients who underwent initial hepatectomy and the 37 patients who underwent repeat resection. The initial resection group had larger tumor size and higher aminotransferase level. There were no differences between initial and repeat hepatectomy with respect to Child-Pugh classifications, serum AFP level, total bilirubin level, tumors number and location, tumor capsule formation, vascular invasion, Edmondson-Steiner grade.

Major resections were performed more frequently in initial hepatectomy. Combined organ resection was common in initial resection (24.6\%). Similarly, initial resection group had more intraoperative blood loss. However, there were no differences between two groups in terms of operating time, clumping time, transfusion requirement, perioperative morbidity and mortality.

The overall 1-year, 3-year, and 5-year survival rates after initial hepatectomy in the whole group of 429 patients were $91.2 \%, 69.4 \%$, and $42.5 \%$, respectively, these were similar to 37 patients after repeat hepatectomy (94.6\%, $70.3 \%$ and $43.7 \%$, respectively).

Figure 1 shows the comparison of survival rates after HCC recurrence according to the types of treatment. The survival rate of patients who had repeat hepatectomy was significantly better than the rates of patients who had non-surgical treatment. The 1-year, 3-year, and 5-year survival rates of patients with TACE were $74.3 \%, 33.3 \%$, and $11.1 \%$, respectively. Patients who underwent local ablation had 1-year, 3-year, and 5-year survival rates of $46.6 \%, 20.3 \%$, and $8.8 \%$, respectively. For patients treated with conservative management after recurrence had survival rates of $24.2 \%, 0 \%$, and $0 \%$, respectively.

Univariate analysis revealed that vascular invasion, multiple recurrent tumors, and a recurrence-free interval of $\leq 1$ year were adverse prognostic factors for survival after repeat hepatectomy (Table 2).
Multivariate analysis indicated that the recurrence-free interval of $\leq 1$ year (risk ratio $=2.665,95 \%$ confidence interval $=0.964-7.364, P=0.05$ ) was the only independent prognostic factor for overall survival after repeat hepatectomy.

\section{Literature search}

\section{A) Quantity and quality of evidence}

This electronic search resulted in the identification of 256 publications. On initial evaluation of these abstracts, 36 studies remained. Manual review of the citation lists identified a further 4 studies. A total of 40 potentially relevant publications were retrieved for further evaluation. Of these, 6 were excluded for the following reasons: 1 study evaluating the impact of obesity on the surgical outcome following repeat hepatic resection patients with recurrent HCC, 2 studies lacks information of survival, 3 were earlier publications from the same treatment center. Another 5 were excluded because the number of patients in each study was fewer than 10. Finally, 29 studies matched the selection criteria and were therefore included. All studies were retrospective in design and their size ranged from 11 to 149 patients. Of these, 28 studies were observational cases series with no control groups and were classified as level-4 evidence [5,8-34], 1 study compared percutaneous radiofrequency ablation versus repeat hepatectomy was classified as level- 3 evidence [35].

\section{B) Selection criteria for repeat hepatectomy}

So far, no consensus has been reached concerning the standard selection criteria for repeat hepatic resection. Generally, patients who had a good performance status and a liver functional reserve, if oncologically radical operation was possible, the patients were selected for hepatectomy $[11-33,35]$.

\section{C) Characteristics of the study population}

Characteristics of the 29 eligible studies are listed in Table 3. These papers described 1149 patients underwent repeat hepatectomy for recurrent HCC. The rate of repeat hepatectomy ranged from $8.7 \%$ to $44.0 \%$ (median $=22.8 \%$ ). The mean age in 17 studies providing data on age ranged from 45.0-66.9 years (median $=59.5)$. Male: female ratio in the pooled data was 4.2: 1 . Median/mean (range) recurrent intervals between the initial and repeat hepatectomy ranged from 6 to 31 (median $=22.4$ ) months. $37.5 \%-83.3 \%$ of patients had solitary intrahepatic recurrence $($ median $=64.2 \%)$.

\section{D) Operative strategy}

At the time of repeat recection, the proportion of patients who underwent minor resection ranged from $71.4 \%$ to $100 \%$ (median $=95.5 \%)$. The median $/$ mean operating time ranged from 136 to $365($ median $=267) \mathrm{min}$. The median/mean estimated blood loss ranged from 211 to $1980($ median $=603) \mathrm{ml}($ Table 4$)$. 
Table 1: Comparison of clinicopathological features, operative procedures and perioperative outcomes between the initial hepatectomy group and the repeat resection group

\begin{tabular}{|c|c|c|c|}
\hline Variables & $\begin{array}{l}\text { Initial Hx } \\
(n=462)\end{array}$ & $\begin{array}{l}\text { Repeat Hx } \\
(\mathrm{n}=37)\end{array}$ & $p$ value \\
\hline $\begin{array}{l}\text { Median age at operation } \\
\text { (years) }\end{array}$ & 49.0 & 52.0 & NS \\
\hline Gender (male/female) & $419 / 43$ & $32 / 5$ & NS \\
\hline HBV-positive & $451(97.6)$ & $37(100)$ & NS \\
\hline Child-Pugh class $A$ & $424(91.8)$ & $37(100)$ & NS \\
\hline Serum AFP > $100 \mathrm{ng} / \mathrm{mL}$ & $212(45.8)$ & $13(35.1)$ & NS \\
\hline Total bilirubin (umol/L) & $14.5 \pm 8.9$ & $16.4 \pm 8.3$ & NS \\
\hline Serum albumin $(g / L)$ & $41.8 \pm 3.6$ & $41.2 \pm 3.7$ & NS \\
\hline Serum ALT (IU/L) & $56.3 \pm 51.8$ & $36.7 \pm 11.4$ & 0.028 \\
\hline Serum AST (IU/L) & $53.4 \pm 52.7$ & $33.0 \pm 10.1$ & 0.007 \\
\hline Tumor size in diameter $(\mathrm{cm})$ & $7.3 \pm 4.8$ & $3.3 \pm 1.9$ & $<0.001$ \\
\hline Tumor location & & & NS \\
\hline Right lobe & $326(70.5)$ & $23(62.1)$ & \\
\hline Left lobe & $134(29.0)$ & $14(37.8)$ & \\
\hline Both lobe & $12(2.5)$ & 0 & \\
\hline Cirrhotic liver & $238(51.6)$ & $20(54)$ & NS \\
\hline Solitary tumor & $374(80.9)$ & $28(75.6)$ & NS \\
\hline Tumor capsule formation & $291(62.9)$ & $26(70.2)$ & NS \\
\hline Vascular invasion & $272(58.2)$ & $19(51.3)$ & NS \\
\hline Edmonson-Steiner grade & & & NS \\
\hline G1-G2 & $31(6.7)$ & $4(10.8)$ & \\
\hline G3-G4 & $431(93.3)$ & $33(89.2)$ & \\
\hline Extent of hepatectomy & & & 0.018 \\
\hline Major resection & $133(28.7)$ & $4(10.8)$ & \\
\hline Minor resection & $329(56.8)$ & $33(89.2)$ & \\
\hline Combined organ resection & $114(24.6)$ & 0 & 0.001 \\
\hline Operation time (min) & $228.6 \pm 68.4$ & $211.8 \pm 67.0$ & NS \\
\hline Clamping time (min) & $18.5 \pm 8.2$ & $16.7 \pm 10.4$ & NS \\
\hline Blood loss (mL) & $690.0 \pm 762.8$ & $364.2 \pm 293.4$ & 0.002 \\
\hline Need for blood transfusion & $64(13.8)$ & $6(16.2)$ & NS \\
\hline Postoperative complication & $147(31.8)$ & $9(24.3)$ & NS \\
\hline Mortality & $4(0.8)$ & 0 & NS \\
\hline $\begin{array}{l}\text { Postoperative hospital stay } \\
\text { (days) }\end{array}$ & $10.6 \pm 3.2$ & $11.5 \pm 3.1$ & NS \\
\hline
\end{tabular}

Hx: hepatectomy. HBV: hepatitis B virus. AFP: alpha-fetoprotein.

ALT: alanine aminotransferase. AST: aspartate aminotransferase.

\section{E) Morbidity and Mortality}

After the repeat hepatectomy, data were available on postoperative complication rate for recurrent $\mathrm{HCC}$ in 12 studies covering 596 patients, with a median (range) morbidity of $23.5 \%$ (6.2-68.2\%). A total of 7 deaths were reported in 24 studies covering 993 patients, giving a mean mortality rate of 0.7 per cent. The reported mortality rate in these studies ranged from 0 to 8.0 per cent (Table 4).

\section{F) Survival}

The overall median survival since the repeat hepatectomy ranged from 21 to 61.5 months, with 1-, 3-, and 5-year 


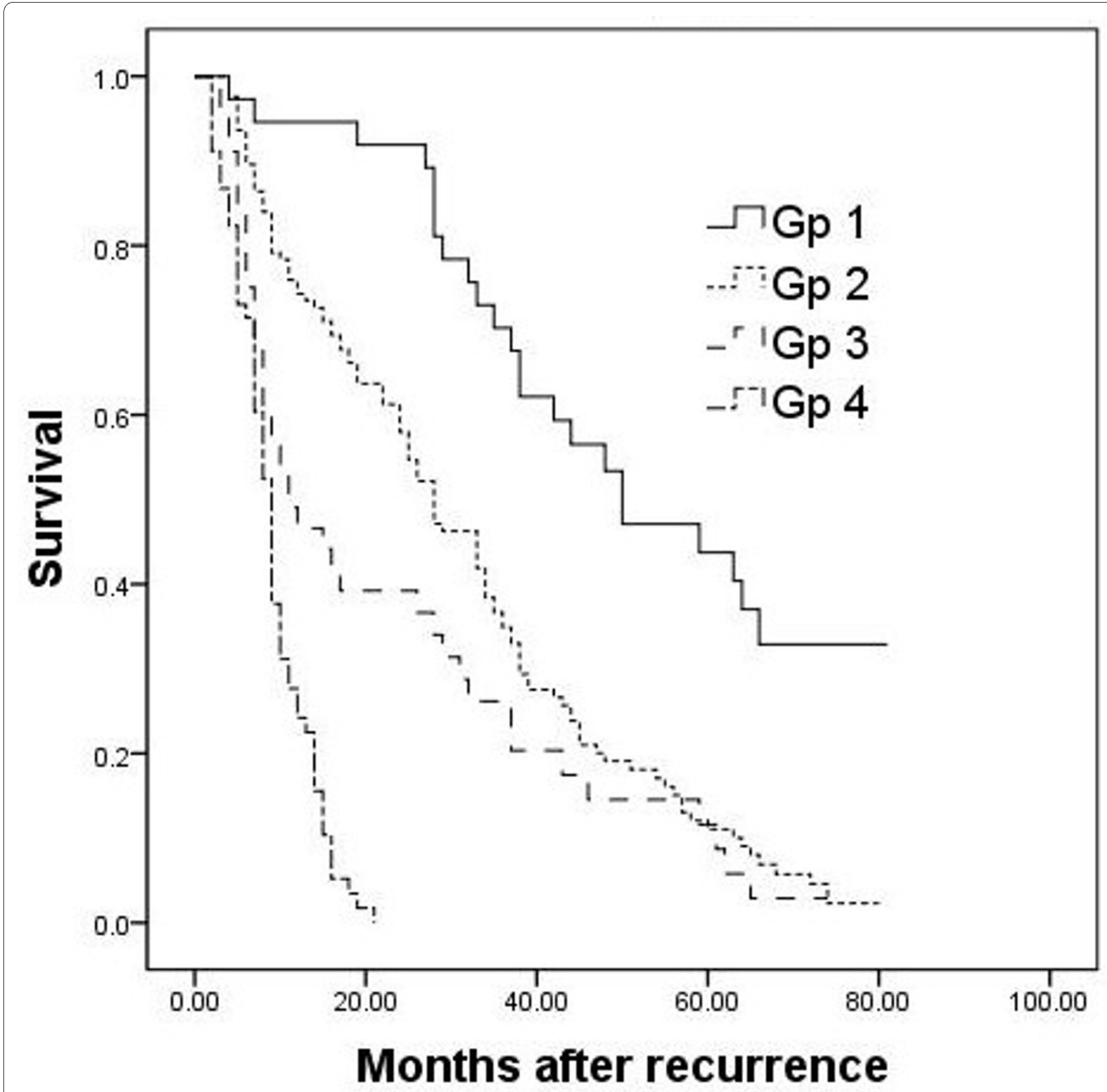

Figure 1 Overall survival from the time recurrence of patients treated with repeat resection (Gp 1), TACE (Gp 2), local ablation (Gp 3), and conservative management (Gp 4).

survival of $69.0 \%$ to $100 \%, 21.0 \%$ to $87.0 \%$, and $25.0 \%$ to $87.0 \%$, respectively (Table 4 ).

\section{G) Significant prognostic factors for survival}

A few studies have identified the independent poor prognostic factors after a repeat hepatic resection. Factors related to initial hepatectomy included the following: portal vein invasion [19,34], multiple lesion [26], and short recurrence-free interval between initial and repeat hepatectomy $(<1$ year [26,35], or $<1.5$ year [34]). Factors related to repeat hepatectomy included the following: female gender, younger age, tumor grade [18], micro- scopic vascular invasion [31], recurrent tumors $>3 \mathrm{~cm}$, and serum albumin level $<35 \mathrm{~g} / \mathrm{L}$ [35].

\section{Discussion}

The postoperative recurrence of $\mathrm{HCC}$ remains the major cause of death and the main obstacle to long-term survival. The remnant liver is the primary site of tumor recurrence, the recurrence rate is $36.8-78 \%$ in current systemic review. Although various therapeutic modalities have been used for the treatment of recurrent HCC, hepatic resection is the only therapy that is potentially 
Table 2: Prognostic factors for overall survival after repeat hepatectomy according to univariate analysis

\begin{tabular}{|c|c|c|c|}
\hline Variables & $\begin{array}{l}\text { No. of } \\
\text { patients }\end{array}$ & $\begin{array}{l}\text { Median survival } \\
\text { (months) }\end{array}$ & $p$ value \\
\hline Age (years) & & & NS \\
\hline$>60$ & 7 & 38 & \\
\hline$\leq 60$ & 30 & 63 & \\
\hline Gender & & & NS \\
\hline Male & 32 & 50 & \\
\hline Female & 5 & 65 & \\
\hline Serum AFP $(n g / m L)$ & & & NS \\
\hline$>100$ & 13 & 50 & \\
\hline$\leq 100$ & 24 & 59 & \\
\hline Serum total bilirubin (umol/L) & & & NS \\
\hline$>20$ & 8 & 35 & \\
\hline$\leq 20$ & 29 & 63 & \\
\hline Serum ALT (IU/L) & & & NS \\
\hline$>40$ & 12 & 37 & \\
\hline$\leq 40$ & 25 & 59 & \\
\hline Serum AST (IU/L) & & & NS \\
\hline$>40$ & 7 & 48 & \\
\hline$\leq 40$ & 30 & 59 & \\
\hline Background liver tissue & & & NS \\
\hline Non-cirrhotic & 17 & 64 & \\
\hline Cirrhotic & 20 & 44 & \\
\hline Tumors capsule formation & & & NS \\
\hline Absent & 11 & 48 & \\
\hline Present & 26 & 64 & \\
\hline Tumors size $(\mathrm{cm})$ & & & NS \\
\hline$>3$ & 15 & 50 & \\
\hline$\leq 3$ & 22 & 59 & \\
\hline Number of tumors & & & 0.040 \\
\hline Solitary & 28 & 64 & \\
\hline Multiple & 9 & 37 & \\
\hline Vascular invasion & & & 0.004 \\
\hline Absent & 18 & 68 & \\
\hline Present & 19 & 38 & \\
\hline Edmonson-Steiner grade & & & NS \\
\hline G1-G2 & 4 & 50 & \\
\hline G3-G4 & 33 & 59 & \\
\hline Recurrence-free interval (year) & & & $<0.001$ \\
\hline$>1$ & 29 & 64 & \\
\hline$\leq 1$ & 8 & 29 & \\
\hline
\end{tabular}

AFP: alpha-fetoprotein. ALT: alanine aminotransferase. AST: aspartate aminotransferase. 
Table 3: Characteristics of the included studies

\begin{tabular}{|c|c|c|c|c|c|c|c|c|c|c|}
\hline First author & Year & $\begin{array}{l}\text { Intrahepatic } \\
\text { recurrences rate (\%) }\end{array}$ & $\begin{array}{l}\text { Median recurrent } \\
\text { Intervals (months) }\end{array}$ & $\begin{array}{l}\text { Resectability } \\
\text { rate (\%) }\end{array}$ & $\begin{array}{l}\text { No. of } \\
\text { repeat } \\
\text { hepatectomy }\end{array}$ & $\begin{array}{l}\text { Male/ } \\
\text { female }\end{array}$ & $\begin{array}{l}\begin{array}{l}\text { Mean age } \\
\text { (years) }\end{array} \\
\end{array}$ & $\begin{array}{l}\text { Liver } \\
\text { cirrhosis (\%) }\end{array}$ & $\begin{array}{l}\text { Solitary recurrent } \\
\text { HCC (\%) }\end{array}$ & $\begin{array}{l}\text { Maxium tumor } \\
\text { size }(<3 \mathrm{~cm})(\%)\end{array}$ \\
\hline Lange [8] & 1989 & -- & 9 & -- & 11 & $9 / 2$ & 45 & 36 & 54.5 & 27 \\
\hline Nakajima [9] & 1993 & 36.8 & -- & 28.5 & 14 & -- & -- & 50 & 64.2 & 64.2 \\
\hline Matsuda [10] & 1993 & 40 & 18 & 44 & 16 & $13 / 3$ & 63.3 & 100 & -- & -- \\
\hline Wu [11] & 1993 & - & -- & -- & 72 & $66 / 6$ & 45.8 & 63.9 & -- & -- \\
\hline Zhou [12] & 1993 & 48.2 & -- & 35 & 65 & -- & -- & -- & -- & -- \\
\hline Kakazu [13] & 1993 & 78 & $26^{*}$ & 11 & 24 & $19 / 5$ & 59.5 & -- & 62.5 & -- \\
\hline Suenaga [14] & 1994 & 61.2 & $33.3^{*}$ & 24.3 & 18 & $13 / 5$ & 56.9 & 88.8 & 72.2 & 67 \\
\hline Lee [15] & 1995 & 40.8 & 18 & 31.2 & 25 & $17 / 8$ & 55.8 & 76 & 60 & 32 \\
\hline Nagasue [16] & 1996 & -- & $21^{*}$ & 30 & 50 & $36 / 14$ & 59 & 76 & 70 & -- \\
\hline Shuto [17] & 1996 & 57 & & 16 & 31 & $27 / 4$ & 60 & 94 & 64.5 & -- \\
\hline $\mathrm{Hu}[18]$ & 1996 & -- & 23 & -- & 59 & $46 / 13$ & 52 & -- & 66.1 & -- \\
\hline Shimada [19] & 1998 & -- & -- & -- & 41 & $33 / 8$ & -- & 56 & 65.8 & 70.7 \\
\hline Arii [20] & 1998 & - & -- & 12.6 & 22 & $16 / 6$ & 60 & 68.2 & 63.6 & -- \\
\hline Farges [21] & 1998 & 67 & -- & 16.8 & 15 & -- & -- & -- & -- & -- \\
\hline Poon [5] & 1999 & 43 & 6 & 10 & 11 & -- & -- & -- & -- & -- \\
\hline Nakajima [22] & 2001 & 60.6 & 31 & 21 & 12 & $10 / 2$ & 62.3 & 41.6 & 83.3 & -- \\
\hline Sugimachi [23] & 2001 & 63.3 & -- & 26 & 78 & -- & -- & -- & -- & -- \\
\hline Tanabe [24] & 2001 & 56.9 & -- & 19.6 & 21 & -- & -- & -- & 76.1 & -- \\
\hline Shen [25] & 2002 & 34.6 & -- & 22.4 & 20 & -- & -- & -- & -- & -- \\
\hline Minagawa [26] & 2003 & 54.7 & -- & 31 & 67 & $56 / 11$ & 62.7 & 68.6 & 55.2 & 76.1 \\
\hline Chen [27] & 2004 & 56.5 & 9.0 & 11.8 & 34 & -- & -- & -- & -- & -- \\
\hline Sun [28] & 2005 & -- & 26.8 & -- & 57 & $52 / 5$ & 52.3 & 85.9 & 82.4 & -- \\
\hline Kobayashi [29] & 2006 & 55.2 & -- & 29 & 60 & -- & -- & -- & -- & -- \\
\hline Tralhão [30] & 2007 & 40 & 27 & 21 & 16 & $14 / 2$ & 61.3 & 93.7 & 43.7 & -- \\
\hline Itamoto [31] & 2007 & 58 & 22.4 & 25 & 84 & $64 / 20$ & 66 & 67 & 63 & 63 \\
\hline Wu [32] & 2009 & 54.4 & 26.3 & 23.2 & 149 & $114 / 35$ & $59 i i^{1 / 20}$ & -- & 79.1 & -- \\
\hline Kawano [33] & 2009 & 67.4 & 12 & 8.8 & 13 & -- & -- & -- & -- & -- \\
\hline Nagano [34] & 2009 & 45.5 & & 22.8 & 24 & $20 / 4$ & 66.9 & -- & 37.5 & -- \\
\hline Liang [35] & 2008 & -- & & -- & 44 & $39 / 5$ & 48.8 & -- & 77.2 & 59.0 \\
\hline
\end{tabular}

* mean 
Table 4: Summary of outcomes reported in the included studies

\begin{tabular}{|c|c|c|}
\hline Variable & No. of studies with available information & Median (range) \\
\hline $\begin{array}{l}\text { Intrahepatic recurrences rate after Initial } \\
\mathrm{Hx}(\%)\end{array}$ & $215,9,10,12-15,17,21-27,29-34$ & $55.2(34.6-78)$ \\
\hline $\begin{array}{l}\text { Median/mean recurrent intervals (months) } \\
\text { after initial } \mathrm{Hx}\end{array}$ & 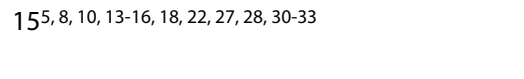 & $22.4(6-33.3)$ \\
\hline Resectability rate (\%) & $23^{5}, 9,10,12-17,20-27,29-34$ & $22.8(8.7-44)$ \\
\hline No. of repeat $\mathrm{Hx}$ & $29^{5,9-35}$ & $1149^{*}$ \\
\hline Mean age (years) & $178,10,11,13-17,20,22,26,28,30-32,34,35$ & $59.5(45-66.9)$ \\
\hline Male (\%) & $198,10,11,13-19,22,26,28,30-32,34,35$ & $81.2(68-91.6)$ \\
\hline Liver cirrhosis (\%) & $15^{8-11,14-17,19,20,22,26,28,30,31}$ & $68.6(36-100)$ \\
\hline Solitary recurrent $\mathrm{HCC}(\%)$ & $198,9,13-20,22,24,26,28,30-32,34,35$ & $64.2(37.5-83.3)$ \\
\hline Maxium tumor size $<3 \mathrm{~cm}(\%)$ & $8^{8}, 9,14,15,19,26,31,35$ & $63.6(27-76.1)$ \\
\hline Minor resection (\%) & $18^{8-18,22,26,30-32,34}$ & $95.5(71.4-100)$ \\
\hline Median/mean operating time (min) & $913,15,16,19,22,26,30,32,34$ & $267(136-365)$ \\
\hline Median/mean blood loss ( $\mathrm{mL}$ ) & $13^{13-16,19,22,26,28-30,32,34,35}$ & $603(211-1980)$ \\
\hline Morbidity (\%) & $12^{10,13,15,16,18,22,28-32,35}$ & $23.5(6.2-68.2)$ \\
\hline Mortality (\%) & $245,8-10,12-23,26,28-32,34,35$ & $0(0-8.0)$ \\
\hline \multicolumn{3}{|l|}{ Overall survival after recurrence } \\
\hline Median time (months) & $88,10,14,15,18,22,28,33$ & $27.1(21-61.5)$ \\
\hline 1-year (\%) & $25^{5,8-22,25-31,34,35}$ & $91.0(69-100)$ \\
\hline 3-year (\%) & $26^{5,8-24,26-31,34,35}$ & $63.4(21.0-87.0)$ \\
\hline 5-year (\%) & $22^{5,9}, 11-14,16,17,19,21,23,24,26-35$ & $48.5(25.0-87.0)$ \\
\hline
\end{tabular}

$\mathrm{Hx}$ : hepatectomy. HCC: hepatocellular carcinoma. ${ }^{*}$ total

curative for liver tumors, and offers patients a chance of long-term survival. However, repeat hepatectomy is considered unsuitable for majority of patients with intrahepatic recurrence. The rate of repeat hepatectomy for HCC recurrence ranged from $7 \%$ to $30 \%$ in the present systematic review (the figure in our current study was $13.4 \%)$. The main reason is the low rate of resectability in patients with intrahepatic recurrence because of the multifocality, location of the tumor, or degree of cirrhosis [33].

Repeat hepatectomy is more technically challenging than initial resection because of impaired liver function due to the progression of hepatitis, the presence of adhesion, and modifications in the anatomy by the previous operation. However, our study and previous reports compared the perioperative outcomes after initial and repeat hepatectomy and did not find any statistically significant. The overall perioperative morbidity rate ranged from $6.2 \%$ to $68.2 \%$ (24.3\% in our series). These complications were easily managed with conservative management. Although data on postoperative death were provided in only 993 of 1149 patients, a mortality rate of 0.7 per cent is very low. Furthermore, repeat hepatectomy can achieve a long-term survival for patients with recurrent HCC. The overall median survival since the repeat hepatectomy ranged from 23 to 56 months, with 5-year survival of $25 \%$ to $87 \%$, and the figure was $43.7 \%$ in our series. Moreover, several studies showed that there was no marked difference in survival after the initial and repeat hepatectomy $[5,11,14,18,19,26,29,32,34]$. These data suggest that repeat hepatectomy is a safely and effective therapy for intrahepatic recurrence.

Predictably, nonsurgical treatment continues to be a factor associated with poor survival of patients with recurrent HCC $[5,24,27]$. The survival outcome of repeat hepatectomy is considerably better than that of nonsurgical or conservative treatment $[5,9,10,12,14-17,21,23-$ $25,27,30,32]$. It should be noted that the favourable results of repeat hepatectomy might partly be due to a high selection of patients with a well preserved liver function and limited intrahepatic tumor spread. Patients who did not undergo repeat hepatectomy may have had poorer liver functional reserve and/or too advanced recurrent tumor [32]. The clinicopathological backgrounds of the patients in the different treatment groups 
were quite different, so comparisons among the various treatments would be of limited value.

Postoperative HCC recurrence is thought to take place in two ways, intrahepatic metastasis (IM) through the portal vein in the residual liver and metachronous, multicentric hepatocarcinogenesis based on chronic hepatitis [36]. Generally, the two kinds of recurrence can roughly be distinguished according to the interval after hepatectomy. The early recurrences ( $\leq 1$ year) may arise mainly from IM, whereas most of the late recurrences ( $>1$ year) are probably multicentric in origin [36]. Early recurrence have been found to be a significant prognostic factor after repeat hepatectomy in two reports [26,35], and our study confirmed the same findings. These data suggested that patients with late recurrences may be more favorable candidates for repeat hepatectomy.

\section{Conclusions}

Repeat hepatectomy can be performed safely and is associated with long-term survival in a subset of patients with recurrent HCC. Although promising, it must also be emphasized that all current available studies are low level evidence. Thus, randomized controlled study is needed to compare repeat hepatectomy and other modalities for recurrent HCC.

\section{Competing interests}

The authors declare that they have no competing interests.

\section{Authors' contributions}

YMZ participated in the design and coordination of the study, carried out the critical appraisal of studies and wrote the manuscript. CJS, BL, ZYL, and ZFY developed the literature search, carried out the extraction of data, assisted in the critical appraisal of included studies and assisted in writing up. ZFY and YCT carried out the statistical analysis of studies. JMY interpreted data, corrected and approve the manuscript. All authors read and approved the final manuscript.

\section{Author Details}

'Department of Hepato-Biliary-Pancreato-Vascular Surgery, the First affiliated Hospital of Xiamen University, Xiamen, China, ${ }^{2}$ Department of Special Treatment and Liver transplantation, Eastern Hepatobiliary Surgery Hospital, Second Military Medical University, Shanghai, China and ${ }^{3}$ Department of Molecular Oncology, Eastern Hepatobiliary Surgery Hospital, Second Military Medical University, Shanghai, China

Received: 11 March 2010 Accepted: 1 July 2010

Published: 1 July 2010

\section{References}

1. Llovet JM, Burroughs A, Bruix J: Hepatocellular carcinoma. Lancet 2003, 362:1907-17.

2. Lau WY, Lai EC: Hepatocellular carcinoma: current management and recent advances. Hepatobiliary Pancreat Dis Int 2008, 7:237-57.

3. Okazaki M, Yamasaki S, Ono H, Higashihara H, Koganemaru F, Kimura S, Kuroda Y, Sato S, Ryu K, Ohtsubo T: Chemoembolotherapy for recurrent hepatocellular carcinoma in the residual liver after hepatectomy. Hepatogastroenterology 1993, 40:320-3.

4. Nakoa N, Kamino K, Miura K, Hayashi T, Ohnishi M, Takayasu Y, Miura T, Okamoto E: Recurrent hepatocellular carcinoma after partial hepatectomy: value of treatment with transcatheter arterial chemoembolization. AJRAm J Roentgenol 1991, 156:1177-9.
5. Poon RT, Fan ST, Lo CM, Liu CL, Wong J: Intrahepatic recurrence after curative resection of hepatocellular carcinoma: long-term results of treatment and prognostic factors. Ann Surg 1999, 229:216-22.

6. Tung-Ping Poon R, Fan ST, Wong J: Risk factors prevention, and management of postoperative recurrence after resection of hepatocellular carcinoma. Ann Surg 2000, 232:10-24.

7. Strasberg SM: Nomenclature of hepatic anatomy and resections: a review of the Brisbane 2000 system. J Hepatobiliary Pancreat Surg 2005, 12:351-5.

8. Lange JF, Leese T, Castaing D, Bismuth H: Repeat hepatectomy for recurrent malignant tumors of the liver. Surg Gynecol Obstet 1989, 169:119-26.

9. Nakajima Y, Ohmura T, Kimura J, Shimamura T, Misawa K, Matsushita M, Sato N, Une Y, Uchino J: Role of surgical treatment for recurrent hepatocellular carcinoma after hepatic resection. World J Surg 1993, 17:792-5.

10. Matsuda Y, Ito T, Oguchi Y, Nakajima K, Izukura T: Rationale of surgical management for recurrent hepatocellular carcinoma. Ann Surg 1993, 217:28-34.

11. Wu MC, Chen H, Yan YQ: Rehepatectomy of primary liver cancer. Semin Surg Oncol 1993, 9:323-6

12. Zhou XD, Yu YQ, Tang ZY, Yang BH, Lu JZ, Lin ZY, Ma ZC, Xu DB, Zhang BH, Zheng YX: Surgical treatment of recurrent hepatocellular carcinom. Hepatogastroenterology 1993, 40:333-6.

13. Kakazu T, Makuuchi M, Kawasaki S, Miyagawa S, Hashikura Y, Kosuge T, Takayama T, Yamamoto J: Repeat hepatic resection for recurrent hepatocellular carcinoma. Hepatogastroenterology 1993, 40:337-41.

14. Suenaga M, Sugiura H, Kokuba Y, Uehara S, Kurumiya T: Repeated hepatic resection for recurrent hepatocellular carcinoma in eighteen cases. Surgery 1994, 115:452-7.

15. Lee PH, Lin WJ, Tsang YM, Hu RH, Sheu JC, Lai MY, Hsu HC, May W, Lee CS: Clinical management of recurrent hepatocellular carcinoma. Ann Surg 1995, 222:670-6.

16. Nagasue $N$, Kohno H, Hayashi T, Uchida M, Ono T, Yukaya H, Yamanoi A: Repeat hepatectomy for recurrent hepatocellular carcinoma. Br J Surg 1996, 83:127-31.

17. Shuto T, Kinoshita H, Hirohashi K, Kubo S, Tanaka H, Tsukamoto T, Okuda T: Indications for and effectiveness of a second hepatic resection for recurrent hepatocellular carcinoma. Hepatogastroenterology 1996 43:932-7.

18. Hu RH, Lee PH, Yu SC, Dai HC, Sheu JC, Lai MY, Hsu HC, Chen DS: Surgical resection for recurrent hepatocellular carcinoma: prognosis and analysis of risk factors. Surgery 1996, 120:23-9.

19. Shimada M, Takenaka K, Taguchi K, Fujiwara Y, Gion T, Kajiyama K, Maeda T, Shirabe K, Yanaga K, Sugimachi K: Prognostic factors after repeat hepatectomy for recurrent hepatocellular carcinoma. Ann Surg 1998, 227:80-5.

20. Arii S, Monden K, Niwano M, Furutani M, Mori A, Mizumoto M, Imamura M: Results of surgical treatment for recurrent hepatocellular carcinoma; comparison of outcome among patients with multicentric carcinogenesis intrahepatic metastasis, and extrahepatic recurrence. $J$ Hepatobiliary Pancreat Surg 1998, 5:86-92.

21. Farges O, Regimbeau JM, Belghiti J: Aggressive management of recurrence following surgical resection of hepatocellular carcinoma. Hepatogastroenterology 1998, 45:1275-80

22. Nakajima $Y$, Ko S, Kanamura T, Nagao M, Kanehiro H, Hisanaga M, Aomatsu Y, Ikeda N, Nakano H: Repeat liver resection for hepatocellular carcinoma. J Am Coll Surg 2001, 192:339-44.

23. Sugimachi K, Maehara S, Tanaka S, Shimada M, Sugimachi K: Repeat hepatectomy is the most useful treatment for recurrent hepatocellular carcinoma. J Hepatobiliary Pancreat Surg 2001, 8:410-6.

24. Tanabe G, Ueno S, Maemura M, Kihara K, Aoki D, Yoshidome S, Ogura Y, Hamanoue M, Aikou T: Favorable quality of life after repeat hepatic resection for recurrent hepatocellular carcinoma. Hepatogastroenterology 2001, 48:506-10.

25. Shen BY, Li HW, Regimbeau JM, Belghiti J: Recurrence after resection of hepatocellular carcinoma. Hepatobiliary Pancreat Dis Int 2002, 1:401-5.

26. Minagawa M, Makuuchi M, Takayama T, Kokudo N: Selection criteria for repeat hepatectomy in patients with recurrent hepatocellular carcinoma. Ann Surg 2003, 238:703-10. 
27. Chen WT, Chau GY, Lui WY, Tsay SH, King KL, Loong CC, Wu CW: Recurrent hepatocellular carcinoma after hepatic resection: prognostic factors and long-term outcome. Eur J Surg Oncol 2004, 30:414-20.

28. Sun HC, Tang ZY, Ma ZC, Qin LX, Wang L, Ye QH, Fan J, Wu ZQ, Zhou XD: The prognostic factor for outcome following second resection for intrahepatic recurrence of hepatocellular carcinoma with a hepatitis B virus infection background. J Cancer Res Clin Oncol 2005, 131:284-8.

29. Kobayashi A, Kawasaki S, Miyagawa S, Miwa S, Noike T, Takagi S, lijima S, Miyagawa Y: Results of 404 hepatic resections including 80 repeat hepatectomies for hepatocellular carcinoma. Hepatogastroenterology 2006, 53:736-41.

30. Itamoto T, Nakahara H, Amano H, Kohashi T, Ohdan H, Tashiro H, Asahara $\mathrm{T}$ : Repeat hepatectomy for recurrent hepatocellular carcinoma. Surgery 2007, 141:589-97.

31. Tralhão JG, Dagher I, Lino T, Roudié J, Franco D: Treatment of tumour recurrence after resection of hepatocellular carcinoma. Analysis of 97 consecutive patients. Eur J Surg Oncol 2007, 33:746-51.

32. Wu CC, Cheng SB, Yeh DC, Wang J, P'eng FK: Second and third hepatectomies for recurrent hepatocellular carcinoma are justified. $\mathrm{Br}$ J Surg 2009, 96:1049-57.

33. Kawano Y, Sasaki A, Kai S, Endo Y, Iwaki K, Uchida H, Shibata K, Ohta M, Kitano S: Prognosis of patients with intrahepatic recurrence after hepatic resection for hepatocellular carcinoma: a retrospective study. Eur J Surg Oncol 2009, 35:174-9.

34. Nagano Y, Shimada H, Ueda M, Matsuo K, Tanaka K, Endo I, Kunisaki C, Togo S: Efficacy of repeat hepatic resection for recurrent hepatocellular carcinomas. ANZ J Surg 2009, 79:729-33.

35. Liang HH, Chen MS, Peng ZW, Zhang YJ, Zhang YQ, Li JQ, Lau WY: Percutaneous radiofrequency ablation versus repeat hepatectomy for recurrent hepatocellular carcinoma: a retrospective study. Ann Surg Oncol 2008, 15:3484-93.

36. Poon RT, Fan ST, Ng IO, Lo CM, Liu CL, Wong J: Different risk factors and prognosis for early and late intrahepatic recurrence after resection of hepatocellular carcinoma. Cancer 2000, 89:500-7.

doi: $10.1186 / 1477-7819-8-55$

Cite this article as: Zhou et al., Repeat hepatectomy for recurrent hepatocellular carcinoma: a local experience and a systematic review World Journal of Surgical Oncology 2010, 8:55

Submit your next manuscript to BioMed Centra and take full advantage of:

- Convenient online submission

- Thorough peer review

- No space constraints or color figure charges

- Immediate publication on acceptance

- Inclusion in PubMed, CAS, Scopus and Google Scholar

- Research which is freely available for redistribution

Submit your manuscript at www.biomedcentral.com/submit
Ciomed Central 